\title{
A constituição da memória e das ideias em torno da disciplina de Linguística no interior do RS*
}

\author{
Caroline Mallmann Schneiders ${ }^{* *}$
}

\begin{abstract}
Resumo: O presente trabalho busca uma melhor compreensão do saber sobre a disciplina de Linguística no interior do RS. Possuímos como corpus de análise os programas da disciplina de Linguística, que datam do final dos anos 60 ao final dos anos 80, do currículo de Letras da Universidade Regional Integrada do Alto Uruguai e das Missões - Campus Santo Ângelo, visando analisar, nesses dados histórico-discursivos, a historicidade e os sentidos constitutivos. A análise por nós empreendida parte dos pressupostos teóricos da História das Ideias Linguísticas, vinculada à Análise de Discurso tal como vem sendo concebida e desenvolvida no Brasil.
\end{abstract}

Palavras-chave: Disciplina; Linguística; História das Ideias Linguísticas.

\section{Considerações iniciais}

Para o desenvolvimento do presente trabalho, tivemos como parâmetro o estudo sobre a institucionalização das ideias linguísticas na UFSM, realizado pela aluna Taís Martins Soares na etapa inicial do projeto Linguística no sul: estudos das ideias e organização da memória dos anos 80 a 2000. A partir disso, temos como interesse, neste artigo, tratar do saber construído sobre a língua em um determinado momento e lugar. Ao abordarmos essa questão, estamos nos referindo e entrando no domínio das ideias linguísticas, porém, em nosso caso, da História das Ideias Linguísticas, visto que buscamos a relação entre a construção do saber sobre a língua com a história. Assim, fundamentamos nosso trabalho na História das Ideias Linguísticas vinculada aos pressupostos teórico-metodológicos da Análise de Discurso (doravante AD), tal como vem sendo desenvolvida no Brasil.

Tomando essa perspectiva, o nosso objetivo principal é compreender a constituição do saber sobre a disciplina de Linguística em universidades mais recentes do interior do Rio Grande do Sul. Para tanto, possuímos como corpus de análise os programas de tal disciplina, datados do final dos anos 60 ao final dos anos 80, da Universidade Regional Integrada do Alto Uruguai e das

\footnotetext{
* Trabalho desenvolvido a partir das reflexões realizadas no decorrer do ano de 2008 junto à iniciação científica, vinculado ao projeto atual $O$ imaginário sobre a lingua na produção do conbecimento linguístico: história e memória, orientado pela Prof. ${ }^{a}$ Dr. Amanda Eloina Scherer.

** Mestranda em Letras - Estudos Linguísticos, no Programa de Pós-Graduação em Letras da UFSM, sob orientação da Prof. ${ }^{a}$ Dr. Amanda Eloina Scherer. E-mail: carolletras2005@yahoo.com.br
} 
Missões - URI ${ }^{1}$-, detendo-nos, em especial, no Campus de Santo Ângelo, situado na região Noroeste do RS.

Procuramos, então, explicitar algumas considerações sobre esses dados histórico-discursivos, as quais procuram enfatizar, principalmente, a memória discursiva, a ideologia e as condições de produção, pois entendemos que elas fazem parte da constituição de nosso corpus de análise. Assim, buscamos compreender a historicidade constitutiva e os efeitos de sentidos inerentes à materialidade discursiva analisada.

\section{Situando noções}

Por estarmos tratando de estudos sobre a linguagem, vinculados à perspectiva discursiva, faz-se necessário mobilizar noções bem como destacar alguns pontos e deslocamentos fundamentais resultantes dessa perspectiva. No que concerne ao objetivo do nosso estudo, é preciso, primeiramente, ter em vista que, de acordo com a perspectiva adotada, o nosso corpus de análise é tomado como um discurso, um objeto linguístico-histórico, que se relaciona tanto com o linguístico, através da língua, como com a história. Assim sendo, a exterioridade é constitutiva do discurso, o que enseja a possibilidade de a ideologia ser apreendida, pois, como afirma Orlandi (2004, p. 151), “a materialidade específica da ideologia é o discurso e a materialidade específica do discurso é a língua".

Nesse sentido, para nós, torna-se importante a relação existente entre a tríade linguagem/sociedade/história, visto que, à luz da $\mathrm{AD}$, a linguagem é pensada em sua materialidade, e, por sua vez, vincula-se a elementos sociais e ideológicos constitutivos na história. Não tratamos, pois, a linguagem desvinculada da história e da sociedade, já que é através delas que se manifestam os elementos sociais e ideológicos. Esses elementos, em consequência, inscrevem-se na história para produzir sentidos, ou seja, a partir da relação dessas noções a língua torna-se não transparente, veiculando efeitos de sentidos.

Os efeitos de sentidos inerentes ao discurso podem ser compreendidos a partir do momento em que nos situamos no acontecimento linguístico e no funcionamento discursivo, que se dá devido ao deslocamento do dado para o fato, deslocamento esse que é essencial para podermos entender a memória discursiva, o funcionamento discursivo dos dados que

\footnotetext{
1 A Universidade Regional Integrada do Alto Uruguai e das Missões (URI) originou-se por meio da integração de instituições de ensino superior isoladas, as quais são pertencentes ao Distrito Geo-Educacional 38. A escolha por esse Campus, em nosso estudo, deve-se ao contexto sóciohistórico diversificado que possui, o qual é marcado pelas Reduções Jesuíticas bem como pela relação com a cultura e língua indígena.
} 
possuímos, pois somente os fatos nos conduzem a essa memória, a qual remete, por sua vez, aos efeitos de sentido da materialidade discursiva.

Entender alguns dos possíveis efeitos de sentido de um determinado discurso, na análise discursiva, é compreender quais os elementos sóciohistórico-ideológicos que o constituem. Desse modo, podemos observar o papel imprescindível da exterioridade na manifestação do discurso, já que essa noção faz parte de sua constituição e de seu funcionamento. Esse vínculo do discurso com a exterioridade implica outro, também inerente ao discurso, e que trata da relação com a ideologia, a qual se articula à memória discursiva do sujeito, fazendo parte das condições de produção do discurso.

A memória discursiva, que está atrelada à(s) ideologia(s) e, em consequência, ao discurso, é também explicitada através da noção de interdiscurso. Essa noção indica que a formação de todo discurso provém da ligação de uma rede de outros dizeres já ditos, os quais "afetam o modo como o sujeito significa em uma situação discursiva dada" (Id., 2001, p.31). A memória discursiva é constitutiva de todo discurso, pois para que este produza sentido é necessário que ele já faça sentido, em outras palavras, que se apóie em algo já posto, sustente-se num já lá.

Orlandi (Ibid.) destaca que o sentido evocado a partir de determinado discurso não é algo fixo e uno, podendo tornar-se outro, mas não qualquer um, pois pertence a um sítio de significação, que, por sua vez, relaciona-se com as condições de produção do discurso. Os sentidos não podem ser qualquer um, uma vez que, segundo a autora, o discurso sofre uma determinação histórica, sendo através dessa determinação que os fatos se constituem, conduzindo-nos à historicidade presente no dizer.

Todo discurso é, nesse sentido, heterogêneo e relacionado diretamente à exterioridade para significar. Entendemos, desse modo, que, por meio da História das Ideias Linguísticas, poderemos ver como está veiculado o saber sobre a disciplina de Linguística ligada a sua exterioridade, ou seja, a um momento e a um lugar determinado. Ao observarmos isso, poderemos, como corrobora Guimarães (2004, p.13), "acompanhar como certos conceitos, certas noções, certas categorias se constituíram e como ao permanecerem mudaram, ou ganharam contornos específicos".

Visando à relação discurso/exterioridade, a análise do nosso corpus parte, inicialmente, de uma breve comparação entre os programas da UFSM e os programas da URI, pois estes são posteriores aos da UFSM. Buscamos, então, aproximar, inicialmente, essas duas instituições, para compreendermos o lugar de onde o nosso corpus analítico parte, ou seja, a sua constituição e os atravessamentos ideológicos que estão inerentes. 


\title{
Considerações sobre os Programas da Disciplina de Linguística
}

\author{
Conforme Altman,
}

foi a partir de 1968 que se concentrou um conjunto de fatores de ordem intelectual e social que permitiu, em vários pontos do país, a solidificação institucional de uma 'Linguística brasileira' e de um jovem grupo de pesquisadores que começaram, a partir de então, a se reconhecer 'linguistas' (2003, p. 47).

Considerando esse dizer de que o ano de 1968 torna-se um marco para os estudos linguísticos, podemos evidenciar um primeiro aspecto que se coloca importante em nosso corpus de análise: o fato de que a disciplina de Linguística I, na URI, foi introduzida após esse marco, em 1969; já na UFSM, foi anterior a essa data, em 1967.

Em uma visão geral sobre os programas da URI, observamos que eles não possuem regularidade, mas semelhanças. Essa constante modificação dos programas é decorrente do "processo de disciplinarização", pois "o discurso do conhecimento, como qualquer outro, está em movimento e não se deixa enclausurar, desenhando seus meandros no fluxo do saber" (Orlandi, 2002, p. $62)$.

Atentando ao primeiro programa da disciplina de Linguística I da URI, do ano de 1969, verificamos que é semelhante ao programa da UFSM, uma das universidades mais antigas do RS. Ao constatarmos essa similaridade dos programas da UFSM e da URI, podemos dizer que a disciplina de Linguística das duas instituições têm muito em comum. Uma das diferenças entre elas está na disposição dos conteúdos, pois os que não estão no primeiro semestre encontram-se no segundo semestre, abordando a Introdução da Linguística Geral e a História da Linguística. Tal divisão consiste $\mathrm{em}^{2}$ :

$1^{\circ}$ SEMESTRE

- Língua, Conceito, Funções

- Langue, Parole

- Sincronia e Diacronia

- Níveis do discurso

- Língua como um grupo de sons

(elementos da $2^{\mathrm{a}}$ articulação)

- Arbitrariedade do signo lingüístico

- A Língua como Sistema: Paradigma

e Sintagma

\section{$2^{\circ}$ SEMESTRE}

- A língua como forma de comportamento social

- Língua e cultura

- A lingüística comparativa

- Os neo-gramáticos

- A lingüística como ciência: Ferdinand de Saussure

- Escolas pós-saussurianas

- História da lingüística entre Hindus, gregos, latinos na Idade Média

2 Os itens dos programas listados em destaque foram transcritos de acordo com a ortografia original das fontes. 
- As mudanças lingüísticas

- Dialetos

- Correção Lingüística

Nesse programa do ano de 1969, Saussure possui um lugar privilegiado, uma vez que se inicia um estudo de suas dicotomias, para depois se ter um estudo da História da Linguística, além de não haver referências explícitas a outros teóricos. Salientamos que não há referência explícita, visto que podemos observar a presença implícita do teórico Martinet através da unidade "Língua como um grupo de sons - elementos da $2^{a}$ articulação".

Tal programa permaneceu até o ano de 1976 e, a partir desse período, percebemos poucas semelhanças entre os programas das duas instituições. Essa diferenciação que a URI busca pode ser decorrente do reconhecimento legal do curso de Letras, que data desse ano, ou seja, os acontecimentos da exterioridade influenciam na produção dos programas. As questões constitutivas do programa de 1977 giram em torno dos seguintes pontos:

\begin{tabular}{|c|c|c|}
\hline 1. A LINGÜÍSTICA & 2. O SIGNO & 3. A LINGUAGEM \\
\hline $\begin{array}{l}\text { 1.1. A lingüística é uma } \\
\text { ciência }\end{array}$ & $\begin{array}{l}\text { 2.1. Os Sinais ou Signos } \\
\text { em Geral }\end{array}$ & $\begin{array}{l}\text { 3.1. Natureza da } \\
\text { linguagem }\end{array}$ \\
\hline 1.2. O objeto da Lingüística & $\begin{array}{l}\text { 2.1.1. Natureza do sinal } \\
\text { ou signo }\end{array}$ & $\begin{array}{l}\text { 3.2. Linguagem e } \\
\text { pensamento }\end{array}$ \\
\hline $\begin{array}{l}\text { 1.3. O método da } \\
\text { Lingüística }\end{array}$ & $\begin{array}{l}\text { 2.1.2. Elementos do } \\
\text { sinal (Peirce) }\end{array}$ & 3.3. Origem da linguagem \\
\hline $\begin{array}{l}\text { 1.3.1. Os principais } \\
\text { métodos lingüísticos }\end{array}$ & $\begin{array}{l}\text { 2.1.3. Caracteres do } \\
\text { sinal ou signo }\end{array}$ & $\begin{array}{l}\text { 3.4. Aquisição da } \\
\text { linguagem }\end{array}$ \\
\hline $\begin{array}{l}\text { 1.3.2. Os princípios } \\
\text { metodológicos (Hjelmslev) }\end{array}$ & $\begin{array}{l}\text { 2.1.4. A Semiótica ou } \\
\text { Semiologia, ciência dos } \\
\text { sinais }\end{array}$ & $\begin{array}{l}\text { 3.5. Elementos da } \\
\text { linguagem }\end{array}$ \\
\hline $\begin{array}{l}\text { 1.4. A Lingüística e seu } \\
\text { caráter interdisciplinar }\end{array}$ & $\begin{array}{c}\text { 2.1.5. Divisões da } \\
\text { Semiótica ou Semiologia }\end{array}$ & $\begin{array}{c}\text { 3.5.1. A dicotomia } \\
\text { "língua-fala" de Saussure }\end{array}$ \\
\hline $\begin{array}{l}\text { 1.5. As divisões da } \\
\text { Lingüística }\end{array}$ & 2.2. O Signo Lingüístico & $\begin{array}{l}\text { 3.5.2. "Competência - } \\
\text { desempenho" de } \\
\text { Chomsky }\end{array}$ \\
\hline 1.6. Sincronia e Diacronia & $\begin{array}{l}\text { 2.2.1. Natureza do } \\
\text { signo lingüístico }\end{array}$ & $\begin{array}{l}\text { 3.5.3. A tricotomia } \\
\text { sistema-norma-fala"de } \\
\text { Cosériu }\end{array}$ \\
\hline $\begin{array}{l}\text { 1.7. Breve histórico da } \\
\text { Lingüística }\end{array}$ & $\begin{array}{l}\text { 2.2.2. Elementos do } \\
\text { signo lingüístico }\end{array}$ & $\begin{array}{l}\text { 3.5.4. Aspectos da } \\
\text { língua: padrão geral, } \\
\text { âmago comum e idioleto } \\
\text { (Hockett). }\end{array}$ \\
\hline \multirow[t]{2}{*}{ 1.8. As tarefas da Lingüística } & $\begin{array}{l}\text { 2.2.3. Caracteres do } \\
\text { signo lingüístico }\end{array}$ & $\begin{array}{l}\text { 3.5.5. Variedades } \\
\text { lingüísticas }\end{array}$ \\
\hline & 2.3. As Duas Articulações & $\begin{array}{l}\text { 3.6. Funções da } \\
\text { linguagem }\end{array}$ \\
\hline
\end{tabular}


Entendemos, através dessa ruptura, que cada instituição começa a abordar as suas perspectivas nos programas, ou melhor, cada instituição passa a trabalhar em condições de produção específicas, as quais são determinadas pela ideologicamente. No programa de 1977, percebemos que as unidades visam a perspectivas diferentes, pois a Linguística é uma disciplina, o Signo é uma noção, e a Linguagem é um conceito. Em relação aos teóricos, verificamos que não se restringe mais a Saussure, uma vez que se tem a presença, constituindo os programas, de Hjelmslev, Peirce, Chomsky, Cosériu, Hockett e, ao fazer referência às funções da linguagem, no ponto 3.6, Jakobson.

Como foi visto na etapa inicial do projeto, através da análise dos programas e ementários das disciplinas de Linguística da UFSM, o conceito de signo de Saussure era designado "sinal" ("O Sinal Lingǘstico" ou "O Caráter do Sinal”), sendo substituído somente em 1976 por signo. Tal designação também é encontrada nos programas da URI, no entanto são utilizadas as duas designações para destacar que tanto pode ser uma quanto a outra, como apresenta o item 2.1 da unidade referente ao Signo, "Os Sinais ou Signos em Geral”. Um ponto interessante que se coloca aqui é que, ao fazer referência ao teórico Peirce, não teria necessidade de colocar as duas expressões, já que em suas formulações há somente a designação de signo, cuja designação faz, portanto, funcionar outros saberes. Além disso, podemos associar como sendo o reflexo das ideias dos primeiros programas das disciplinas de Linguística do RS, ou seja, é o reflexo do já dito, a memória discursiva afetando o modo da formulação desses dizeres.

O programa de 1977 permanece até 1986. Em 1987, o programa de Linguística I sofre novas alterações: observamos a introdução de novas subáreas da Linguística, como a Psicolinguística e a Sociolinguística, as quais fazem parte da constituição dos programas. Também verificamos a presença, porém não explicitamente, ou não mostrada, da $\mathrm{AD}$. Constatamos essa inserção da $\mathrm{AD}$ a partir da bibliografia do programa, pois é possível verificar a presença de A linguagem e seu funcionamento, de Eni Orlandi, obra que deu consistência aos estudos da AD no Brasil, no início dos anos 80.

Há, então, a introdução de novos saberes, contudo estes não possuem um espaço próprio, pois estão inseridos juntamente com outras questões (1. A Lingüística, 2. O signo, 3. A Linguagem). Verificamos uma determinação em nosso corpus do momento pelo qual os estudos sobre a linguagem estavam passando, uma vez que é nesse período que a Sociolinguística, a Psicolinguística e a AD buscam a disciplinarização de seus saberes. Logo, esses programas estão determinados historicamente, ou seja, as ideias vigentes sobre os estudos da linguagem estão diretamente ligadas a esses discursos que tratam sobre o saber da língua. Explicamos isso pelo fato de a produção do discurso 
estar ligada à ideologia, a qual se materializa através do discurso, apontando para a sua historicidade, bem como para seus sentidos.

\section{Considerações finais}

A partir dos programas de Linguística I da URI foi possível verificar que essa disciplina institucionalizou-se, inicialmente, a partir dos dados referentes ao ensino do saber sobre a língua no Centro do Estado. Desse modo, o ensino da Linguística na URI foi, primeiramente, uma forma de extensão do ensino que se fazia nas universidades mais antigas, especificamente, na UFSM.

O primeiro gesto de interpretação desses dados histórico-discursivos que nos foram disponibilizados levou-nos à constatação de que as ideias saussurianas, como era o esperado, estão presentes em todos os programas da disciplina de Linguística I. Observamos que os primeiros programas abordavam quase que exclusivamente os conceitos de Saussure, mas aos poucos as unidades constitutivas dos programas foram modificando-se, ganhando os chamados "contornos específicos", devido ao momento histórico em que estavam inseridas. Logo, as condições de produção dos programas estão afetadas pelo momento histórico em que os estudos linguísticos estão inseridos, visto que, conforme vão surgindo novas perspectivas, os programas as abordam, ou seja, os programas são vulneráveis ao momento dos estudos linguísticos.

Logo, procuramos destacar, em nosso estudo, algumas questões, bem como estabelecer relações que nos proporcionam uma melhor compreensão da constituição do saber sobre a disciplina de Linguística no contexto interiorano sul-rio-grandense. Por fim, podemos afirmar que esse estudo abre espaço para novas reflexões e instiga para um entendimento/questionamento da forma atual da disciplina de Linguística nos cursos de Letras do RS.

\section{Referências}

ALTMAN, Cristina. A pesquisa lingüística no Brasil (1968-1988). São Paulo: Humanitas, 2003.

GUIMARÃES, Eduardo. História da Semântica. Campinas: Pontes, 2004.

ORLANDI, Eni P.; GUIMARÃES, Eduardo (orgs.). Institucionalização dos estudos da Linguagem: A Disciplinarização das Ideias Lingüísticas. Campinas: Pontes, 2002.

ORLANDI, Eni. Análise de discurso: princípios e procedimentos. Campinas: Pontes, 2001.

Pontes, 2004.

Interpretação: autoria, leitura e efeitos do trabalho simbólico. 4.ed. Campinas: 